OPEN ACCESS

Edited by:

Hugo Morais,

University of Lisbon, Portugal

Reviewed by:

Yushuai Li,

University of Denver, United States Kenneth E. Okedu, National University of Science and Technology (Muscat), Oman

*Correspondence: Xiaoxin Wu wu.xx@ntu.edu.cn Dejian Yang dejian@ntu.edu.cn

Specialty section: This article was submitted to Process and Energy Systems Engineering, a section of the journal Frontiers in Energy Research

Received: 19 October 2021 Accepted: 29 November 2021 Published: 03 January 2022

Citation:

Si X, Wu X, You F, Yuan $H, X u Y$ and Yang D (2022) Primary Frequency Stability Support of a DFIG in Association With Pitch Angle Control. Front. Energy Res. 9:798037. doi: 10.3389/fenrg.2021.798037

\section{Primary Frequency Stability Support of a DFIG in Association With Pitch Angle Control}

\author{
Xiuli $\mathrm{Si}^{1}$, Xiaoxin $\mathrm{Wu}^{2 *}$, Feng You ${ }^{1}$, Hongliang Yuan ${ }^{1}$, Yien $\mathrm{Xu}^{2}$ and Dejian Yang ${ }^{3 *}$ \\ ${ }^{1}$ Alpha ESS Co., Ltd., Nantong, China, ${ }^{2}$ School of Electrical Engineering, Nantong University, Nantong, China, ${ }^{3}$ Key Laboratory of \\ Modern Power System Simulation and Control \& Renewable Energy Technology Ministry of Education (Northeast Electric Power \\ University), Jilin, China
}

For an electric power grid that has large penetration levels of variable renewable energy including wind generation and photovoltaics, the system frequency stability is jeopardized, which is manifest in lowering frequency nadir and settling frequency. This paper suggests an enhanced primary frequency response strategy of a doublyfed induction generator (DFIG) in association with pitch angle control. The DFIG works in de-loaded operation with a certain reserve power via pitch angle control prior to disturbances for frequency regulation. To address this, a function of the pitch angle is employed that decreases the pitch angle with time to slowly feed the active power to the power gird. The simulation results demonstrate the effectiveness and feasibility of the proposed primary frequency response strategy including the settling frequency and frequency nadir.

Keywords: variable renewable energy, frequency support, DFIG, settling frequency, frequency stability

\section{INTRODUCTION}

When disturbances occur in a power system, the conventional synchronous generators (CSGs) intrinsically release kinetic energy in the rotor to compensate for the power imbalance as an inertial response; as a result, the system frequency declines (Kundur, 1994; Yang et al., 2018). Once the system frequency decreases beyond the deadband, the primary frequency response (PFR) is activated to arrest the frequency decline and stabilize the system frequency (which calls the settling frequency) (Bevrani, 2009; North American Electric R, 2015). To restore the system frequency to the nominal value, secondary frequency responses (SFRs) of CSGs are activated (Eto et al., 2010). During the frequency regulation process, if the maximum frequency nadir exceeds the threshold, low frequency relays are activated to avoid the system frequency decline; in addition, if the settling frequency is not located in the acceptable range, the SFRs would not be activated (Li et al., 2018; Sarasúa et al., 2021).

As the increasing problems of environmental pollution, renewable energy power generation has developed rapidly (Li et al., 2021; Zhang et al., 2021). As one of the most popular variable renewable energies, wind generation with power electronics has developed rapidly in recent years (Nasirpour et al., 2021; Wang et al., 2021). As a result, doubly-fed induction generators (DFIGs) replace the CSGs in power systems for generating active power (Hansen et al., 2016). However, since the DFIG is connected to the electric power grid via back-to-back power electronic devices with DC-link, it is unable to participate in frequency responses including inertia response and primary frequency response (Aziz et al., 2018; Yang 


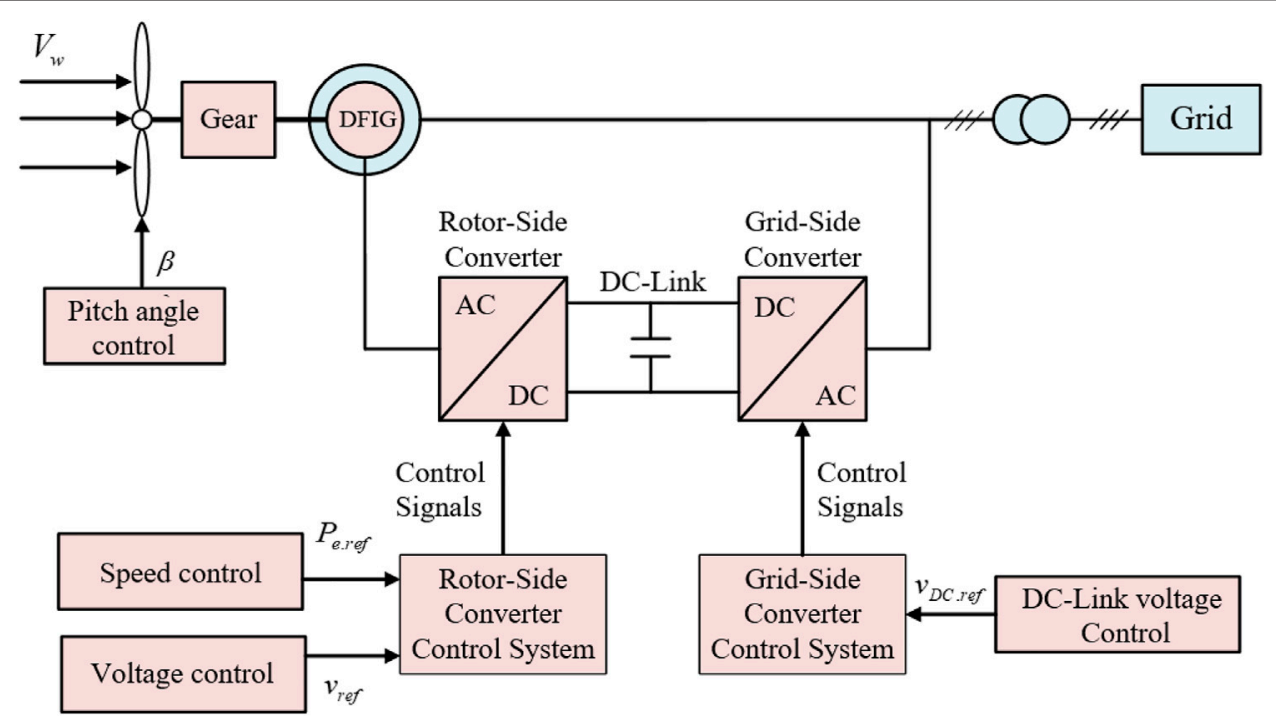

FIGURE 1 | Typical configuration of the DFIG.

et al., 2022). As a result, the high wind power penetration integrated in a power system might result in a severe challenge on frequency stability (Hydro Québec TransÉnergie, 2009; Kim et al., 2019). This means that the high wind power penetration increases the possibility for activation the relays and inactivation of SFR. To solve this, additional defense plans should be deployed, e.g., interruptible loads, energy storage systems, and quickstarting generators (Eto et al., 2010; Shi et al., 2021); nevertheless, these plans require additional investments.

The DFIG can temporarily increase its output power to emulate inertia response by releasing the kinetic energy to the gird (Vidyanandan and Senroy, 2014; Zhong et al., 2021), thereby reducing the possibility for activation the relays. In (Attya et al., 2018; Ye et al., 2019), the schemes increase the output power based on the frequency deviation, rate of change of frequency, and both of them. The schemes in (Yang et al., 2018; Kheshti et al., 2019; Yang et al., 2022) increase the output power based on the predefined reliable function, temporary function, and adaptive function. However, the maximum power point tracking operation is implemented prior to disturbances, even though the DFIG has a large potential for frequency regulation; in the case of a low wind speed condition or decreasing wind speed condition, the available kinetic energy is insufficient (Vidyanandan and Senroy, 2013).

This study suggests an enhanced PFR strategy of a DFIG based on pitch angle control to boost the settling frequency and maximum frequency deviation. To address this, a function of the pitch angle is employed that decreases the pitch angle with time to generate the additional active power. The DFIG works in de-loaded operation with a certain reserve power for frequency regulation prior to disturbances. The enhanced PFR strategy performance is indicated using EMTP-RV simulator under various scenarios with different wind speed conditions and wind penetrations.

\section{MODELING AND CONTROL OF A DOUBLY-FED INDUCTION GENERATOR}

Figure 1 illustrates the typical configuration of the DFIG including wind turbine model, induction generator model, and back-to-back power electronic devices (Lee et al., 2016; Zhu et al., 2021).

The wind turbine model is used to capture the mechanical power from the wind. The captured power $\left(P_{m}\right)$ is depicted by:

$$
P_{m}=0.5 \rho \pi R^{2} v_{w}^{3} c_{P}(\lambda, \beta)
$$

where $\rho$ and $A$ respectively indicate the air density and swept area; $\beta$ and $\lambda$ respectively are pitch angle and the tip-speed ratio; $c_{p}$ and $v_{w}$ respectively indicate the power coefficient and wind speed.

In this paper, the expression of the power coefficient $c_{p}$ is given as:

$$
c_{P}(\lambda, \beta)=0.645\left\{0.00912 \lambda+\frac{-5-0.4(2.5+\beta)+116 \lambda_{i}}{e^{21 \lambda_{i}}}\right\}
$$

where

$$
\begin{gathered}
\lambda_{i}=\frac{1}{\lambda+0.08(2.5+\beta)}-\frac{0.035}{1+(2.5+\beta)^{3}} \\
\lambda=\frac{\omega_{r} R}{v_{w}} .
\end{gathered}
$$

During MPPT control, $\mathrm{c}_{p}$ is at the maximum value $\left(\mathrm{c}_{\mathrm{P}, \max }\right)$ when $\lambda$ is regulated at the optimal $\lambda\left(\lambda_{\text {opt }}\right)$. Hence, the reference for MPPT control is derived via substituting (4) in (Eq. 1), as in (Eq. 5).

$$
P_{\mathrm{MPT}}=\frac{1}{2} \rho \pi R^{2}\left(\frac{\omega_{r} R}{\lambda_{\mathrm{opt}}}\right)^{3} c_{p, \max }=k_{g} \omega_{r}^{3}
$$


A

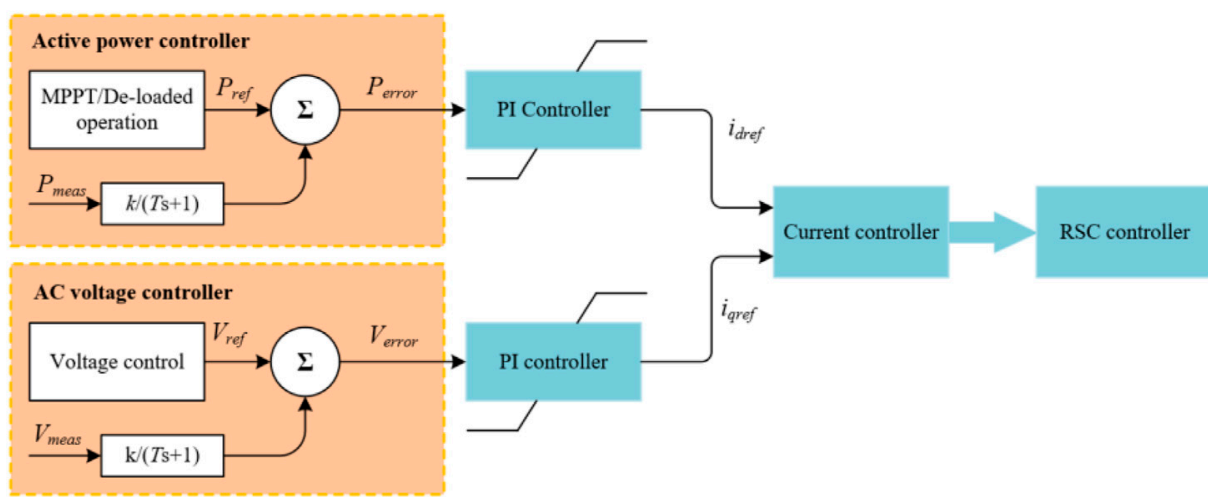

B

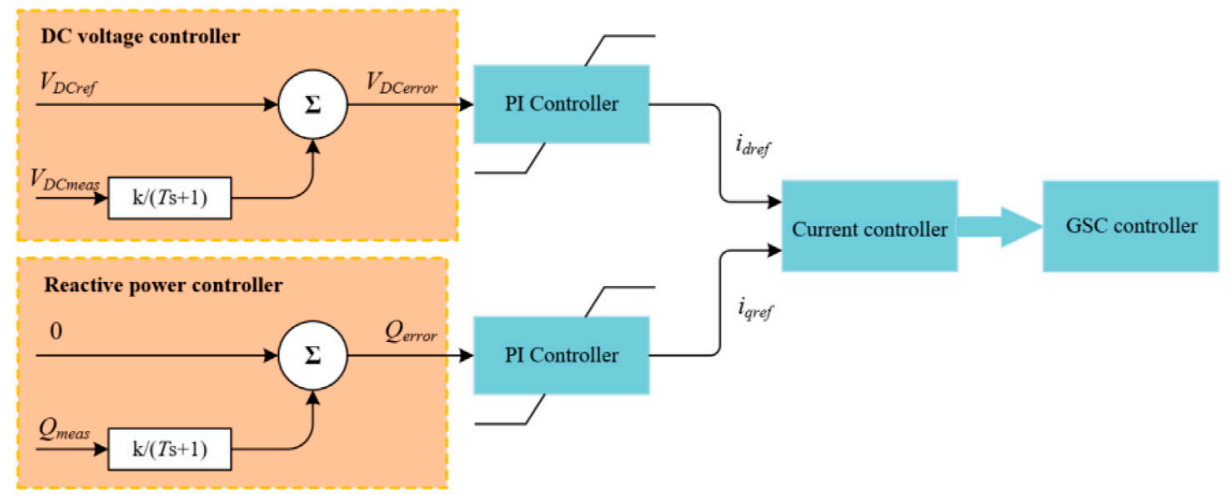

C

GSC controller

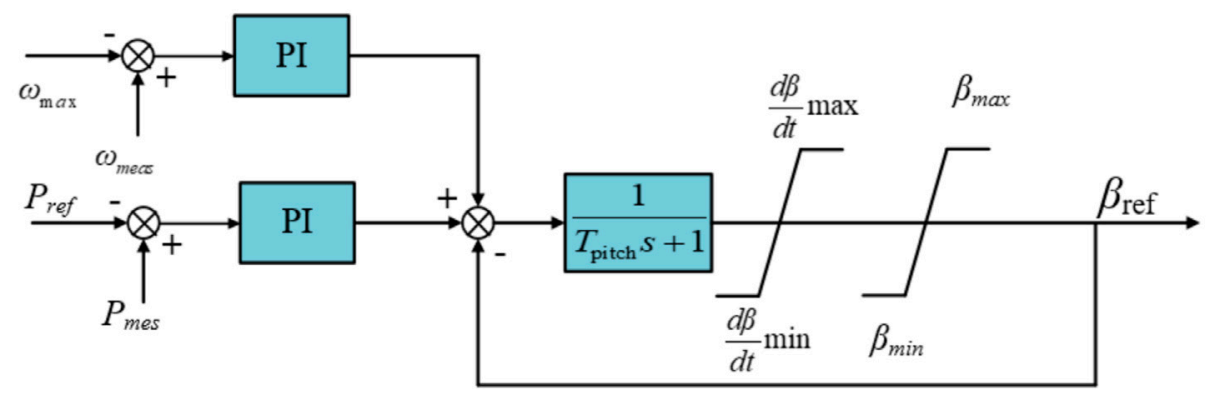

Pitch angle controller.

FIGURE 2 | Control diagram of the DFIG. (A) RSC controller. (B) GSC controller. (C) Pitch angle controller.

$$
k_{g}=\frac{1}{2 \lambda_{\mathrm{opt}}^{3}} C_{p, \max }\left(\lambda_{\mathrm{opt}}, 0\right) \rho \pi R^{5}
$$

where $k_{g}$ is constant coefficient of MPPT control calculated by (Eq. 6).

Figures 2A-C display the controllers of rotor-side converter, gird-side converter, and pitch angle, respectively. The aims of RSC controller are to regulate active power (torque) of the DFIG injected to the power grid and the voltage of the DFIG, respectively, as displayed in Figure 2A. The objective of the GSC controller is to keep DC-link voltage at reference values, as displayed in Figure 2B. The aim of the pitch angle controller is to achieve the de-loaded operation of the DFIG in the study, as shown in Figure 2C (Muljadi and Butterfield, 2001).

\section{PROPOSED ENHANCED PRIMARY FREQUENCY RESPONSE STRATEGY OF A DOUBLY-FED INDUCTION GENERATOR}

Figure 3 and Figure 4 illustrate the control concepts of the overspeed and pitch angle control strategies for de-loaded operation, respectively. The red solid line and blue solid line indicate the electrical output power of MPPT operation and 


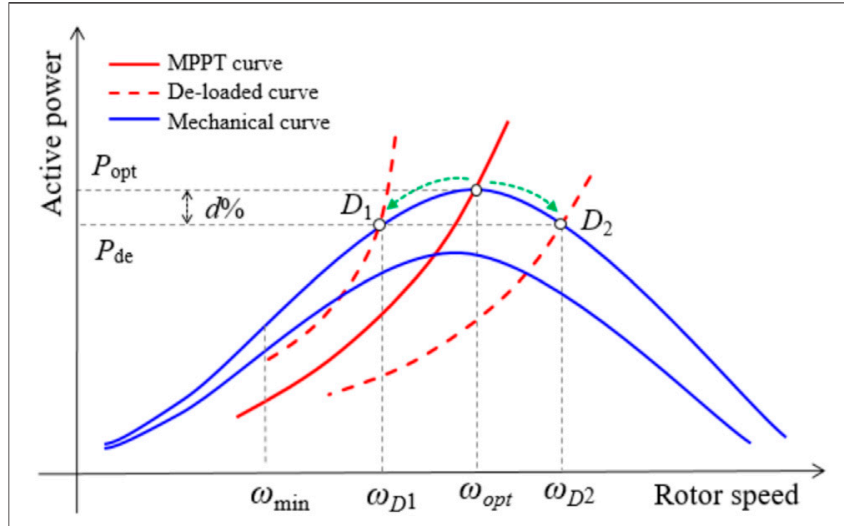

FIGURE 3 | Control concept of overspeed strategy.

mechanical power curves, respectively. The mechanical power retains an optimal value $\left(P_{\text {opt }}\right)$ achieved by the MPPT operation at the optimal rotor speed $\left(\omega_{\text {opt }}\right)$. Generally, the DFIG can implement pitch angle control and over-speed control to ensure the de-loaded operation (Kheshti et al., 2019), as represented by the red dotted lines in Figures 3, 4 . The green dotted line means the moving trajectory for de-loaded operation.

As in Figure 3, de-loaded operation of the DFIG is able to be achieved by either acceleration or deceleration of the rotor speed, as indicated the left and right hand operating points of $D_{1}$ and $D_{2}$ in Figure 3. In the case of decreasing wind speed conditions, the operating point of $\mathrm{D}_{1}$ trends to decrease to the minimum rotor speed so as to result in stalling of the rotor speed. On the other hand, the operating point of $\mathrm{D}_{2}$ trends to increase to the maximum rotor speed so as to store more kinetic energy for frequency regulation. As a result, to ensure the safe and stable operation of the DFIG, overspeed control should be chosen for the WTG rather than low-speed control (Hu et al., 2019).

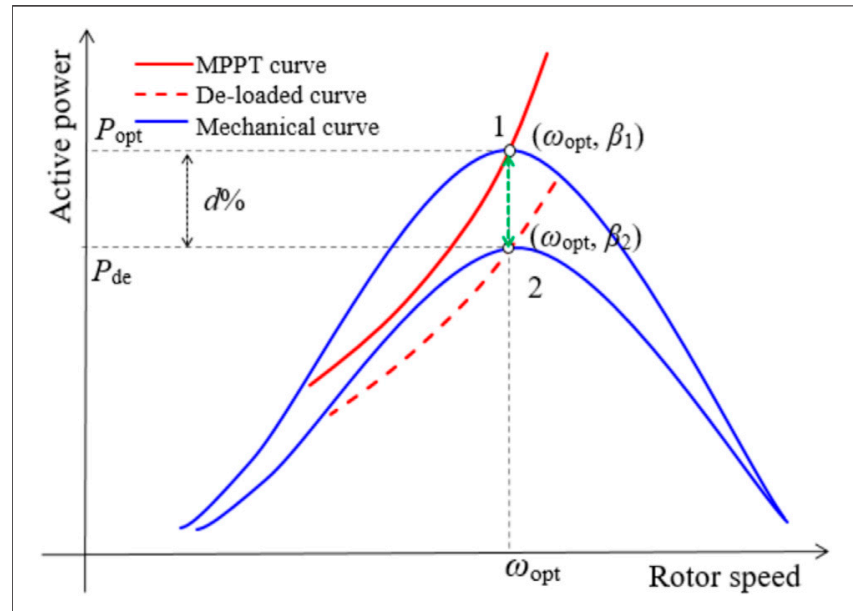

FIGURE 4 | Control concept of pitch angle control strategy.

Based on (Eq. 1), the DFIG can increase the pitch angle to achieve de-loaded operation, as shown in Figure 4. Since $\beta_{2}$ is larger than $\beta_{1}$, the power coefficient decreases so as to reduce the captured mechanical power and accomplish the spinning reserve power ( $\mathrm{Fu}$ et al., 2017). Even though the overspeed control strategy has more rapid response and results less mechanical wear, but is suitable for part of wind speed conditions, the pitch angle control is able to implement for full wind speed conditions.

The spinning reserve power (d\%) of the DFIG can be calculated by

$$
d \%=\left(P_{\text {opt }}-P_{d e}\right) / P_{\text {opt }} \times 100 \%
$$

Based on (Eq. 7), the power coefficient for de-loaded operation $\left(C_{p}\right.$, deload $)$ can be derived as in:

$$
C_{p, \text { deload }}=(1-d \%) C_{p, \max }
$$

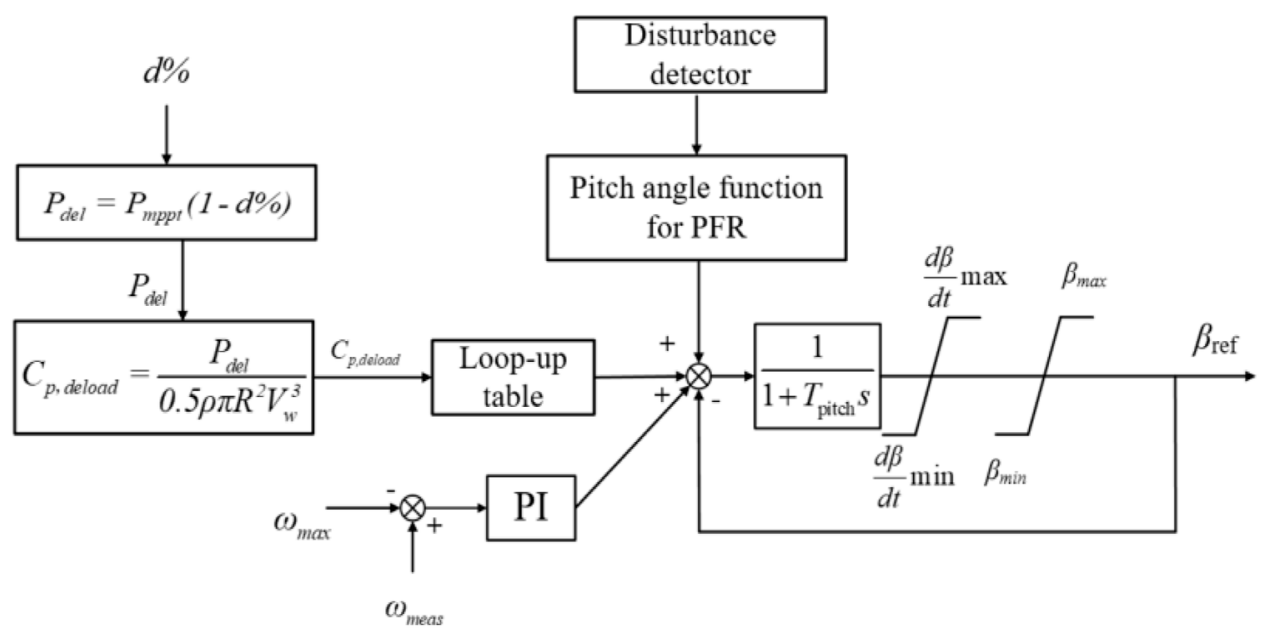

FIGURE 5 | Control diagram of the proposed enhanced PFR strategy of the DFIG based pitch angle. 


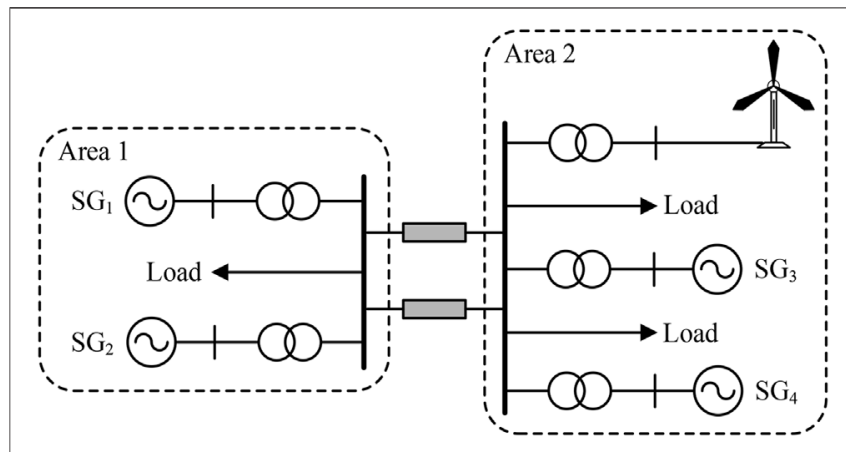

FIGURE 6 | Test model system with four CSGs two areas.

Thus, the power reference during de-loaded operation mode $\left(P_{d e}\right)$ is represented as

$$
P_{d e}=0.5 \rho \pi R^{2} C_{p, \text { deload }}
$$

As in (Fu et al., 2017), based on the low-order system frequency response model, the expressions of the maximum frequency deviation and settling frequency are given as:

$$
\begin{gathered}
\Delta f_{\text {nadir }}=\frac{K \Delta P}{\mathrm{DK}+1}\left(1+\sqrt{1+\varsigma^{2}}\right) \alpha^{-\varsigma \omega_{n} t_{\text {nadir }}} \\
f_{\text {settling }}=f_{\text {nom }}-\frac{K-\Delta P}{D}
\end{gathered}
$$

where $\Delta f_{\text {nadir }}$ and $f_{\text {settling }}$ are the maximum frequency deviation and settling frequency, respectively. $K$ and $D$ are the setting of PFR and damping of the CSGs, respectively. $\alpha$ and $\varsigma$ are the coefficient during the derived process and damping ratio, respectively. $t_{\text {nadir }}$ is the instant of the maximum frequency deviation. $\Delta P$ is the power imbalance calculated by the difference between the power variation of the DFIG and size of disturbance.

Based on (Eqs. 10, 11), if the DFIG increases the output power following a disturbance, the equivalent power imbalance becomes small so that the maximum frequency deviation and settling frequency become better. This means that the DFIG can provide the capability of PFR.

Figure 5 illustrates the control diagram of the enhanced PFR strategy of the DFIG. If the DFIG decreases the pitch angle to capture more wind power by the wind turbine. The output power of the DFIG can be increased to compensate for the power imbalance. Thus, after the system frequency exceeds the deadband (detecting a disturbance), this study suggests a function related to pitch angle and time to participate in PFR, as in (Eq. 12). As time goes on, the pitch angle decreases, the DFIG captures more mechanical power from the wind so as to generate more active power to the grid for frequency support.

$$
\beta_{r e f}(t)=\beta\left(t_{0}\right) \times\left[1-\frac{1}{\Delta t}\left(t-t_{0}\right)\right]
$$

where $\beta_{\text {ref }}$ is the reference of pitch angle, $\beta\left(t_{0}\right)$ is the pitch angle at the instant when a disturbance is detected, $\Delta t$ means the duration for decreasing pitch angle.

As in (Eq. 12), the setting of $\Delta t$ decides on the performances in terms of improvement of the frequency nadir and settling frequency. With a large settling of $\Delta t$, the pitch angle gradually decreases so that the output power of the DFIG gradually increases to $P_{\text {opt }}$; meanwhile, even though the large $\Delta t$ is better for causing less mechanical stress on the pitch angle, the benefit for improving the maximum frequency deviation becomes less. On the other hand, the small $\Delta t$ is better for improving the PFR capability, however, it might cause mechanical stresses on the pitch angle control system. Normally, the setting should be in second-scale so as to be unable to result in mechanical fatigue of the pitch angle control system.

As shown in Figure 5, after detecting a disturbance, the output power of the DFIG increases toward to $P_{\text {opt }}$ with the decreasing pitch angle from operating point 2 to operating point 1 ; thereafter, the DFIG converges at $\omega_{\text {opt }}$ while the pitch angle decreases to zero. Since the output power increases in comparison with MPPT operation, the maximum frequency deviation and settling frequency are able to be enhanced.

\section{SYSTEM LAYOUT}

Figure 6 displays a model system with two areas and four CSGs to investigate the performance of the enhanced PFR strategy. CSGs are: two 200-MVA with the inertia time constant of $5.0 \mathrm{~s}$, and two 150-MVA with the inertia time constant of $4.3 \mathrm{~s}$. They are assumed as steam turbine generators for modeling low ramping capability (5\% of PFR). Figure 7 illustrates the configuration of the type B steam governor model, as modeled

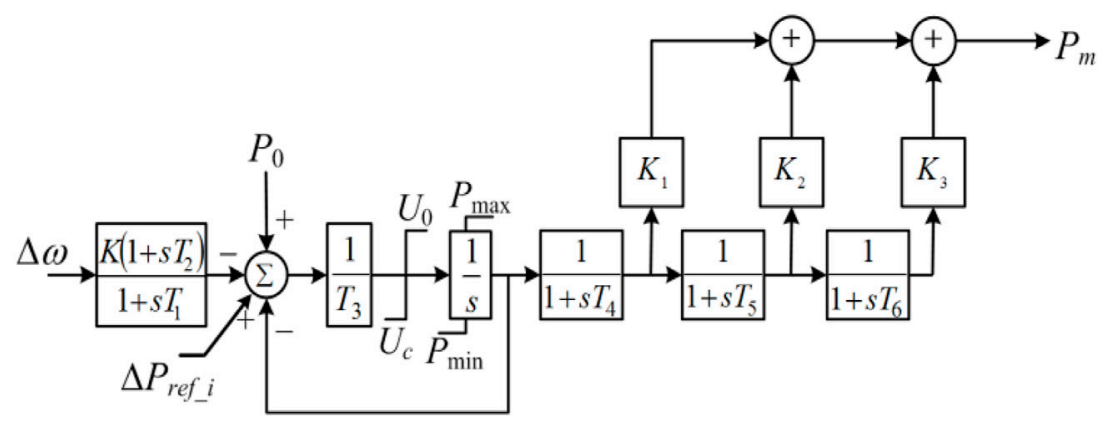

FIGURE 7 | IEEEG1 steam governor model. 
TABLE 1 | Parameters of the IEEEG1 steam governor model.

\begin{tabular}{lllllll}
\hline $\boldsymbol{K}$ & $\boldsymbol{K}_{\mathbf{1}}$ & $\boldsymbol{K}_{\mathbf{2}}$ & $\boldsymbol{K}_{\mathbf{3}}$ & $\boldsymbol{T}_{\mathbf{1}}$ & $\boldsymbol{T}_{\mathbf{2}}$ & $\boldsymbol{T}_{\mathbf{3}}$ \\
\hline 20 & 0.3 & 0.4 & 0.3 & 0.1 & 1.0 & 0.25 \\
$T_{4}$ & $T_{5}$ & $T_{6}$ & $U_{\circ}$ & $U_{c}$ & $P_{\max }$ & $P_{\min }$ \\
0.3 & 10 & 0.4 & 0.1 & -0.2 & 1 & 0.4
\end{tabular}

in (Byerly et al., 1973). The specific parameters of the IEEEG1 steam governor model are shown in Table 1. In addition, a DFIG based wind farm is integrated into the model system though a transformer. The detailed parameters are referred in (Lee et al., 2016) (Table 2).

To explore the effectiveness and feasible of the proposed enhanced PFR strategy, three cases with different wind speed
TABLE 2 | Parameters of the DFIG.

\begin{tabular}{lll} 
Item & Values & Units \\
\hline Nominal stator voltage & 2.3 & $\mathrm{kV}$ \\
Nominal apparent power & 5.5 & $\mathrm{MVA}$ \\
Nominal active power & 5.0 & $\mathrm{MW}$ \\
Magnetizing reactance & 2.9 & $\mathrm{p} . \mathrm{u}$ \\
Stator leakage reactance & 0.18 & $\mathrm{p} . \mathrm{u}$ \\
Rotor resistance & 0.016 & $\mathrm{p} . \mathrm{u}$ \\
Rotor leakage reactance & 0.16 & $\mathrm{p} . \mathrm{u}$ \\
Stator resistance & 0.023 & $\mathrm{p} . \mathrm{u}$ \\
Inertia constant & 5.0 & $\mathrm{~S}$ \\
Stable operating range of $\omega_{r}$ & $0.70-1.25$ & $\mathrm{p} . \mathrm{u}$ \\
Rated, cut-in, and cut-out speeds & 11,4, and 25 & $\mathrm{~m} / \mathrm{s}$ \\
Based value of rotor speed & 235.62 & $\mathrm{rad} / \mathrm{s}$ \\
Based value of torque & 21.78 & $\mathrm{kNm}$
\end{tabular}
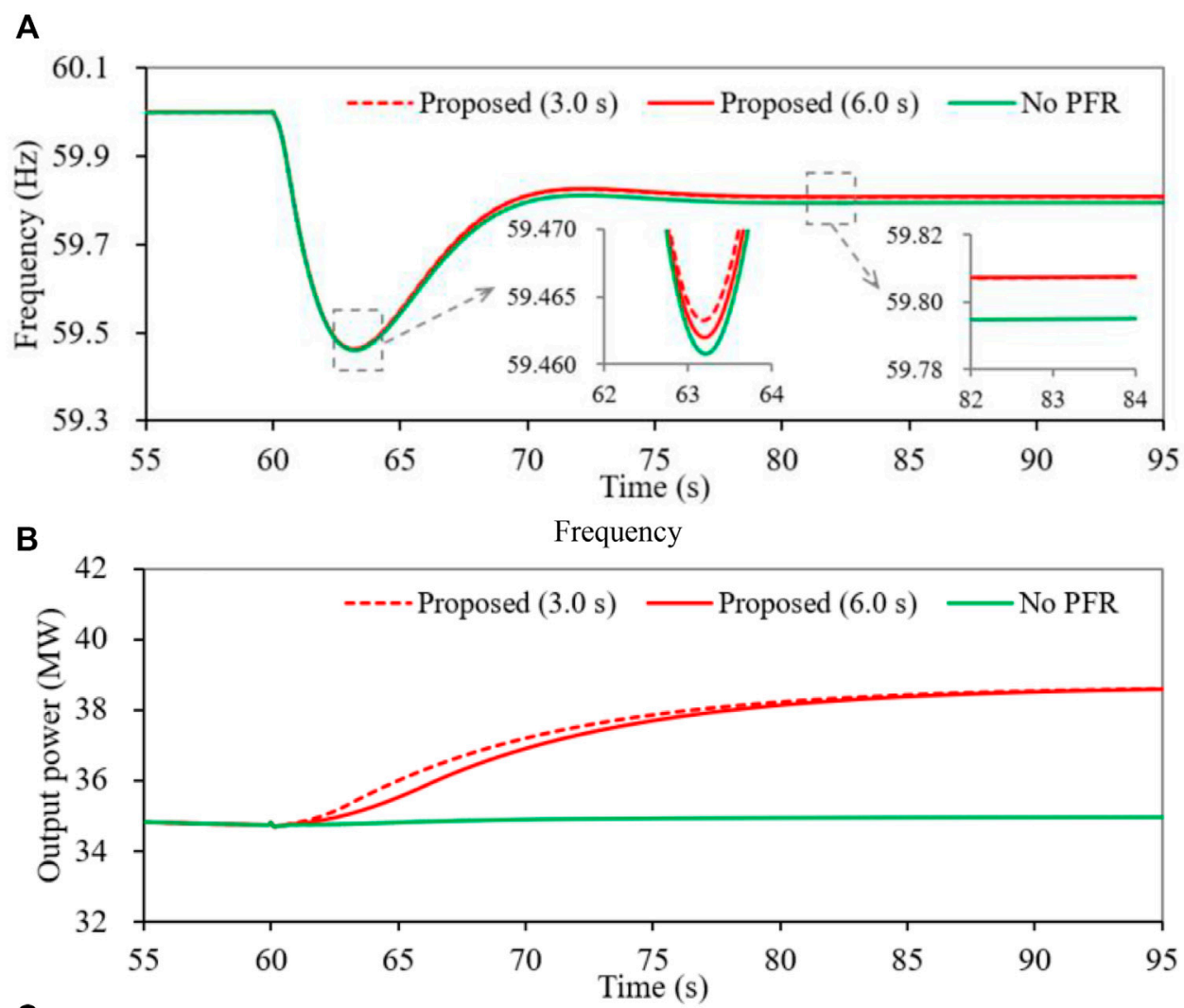

C

Active power

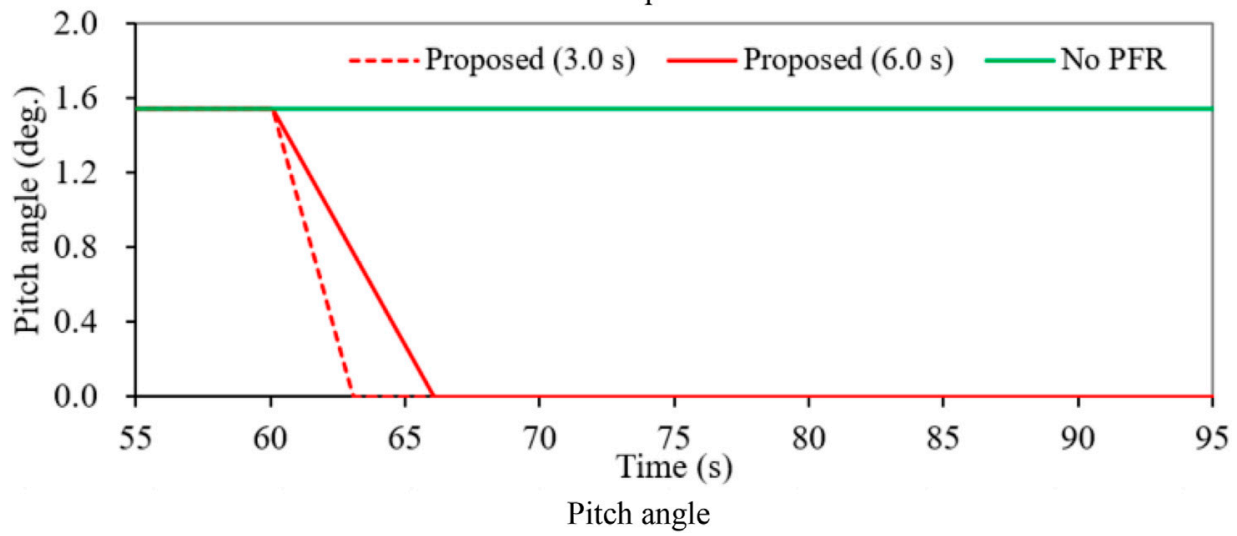

FIGURE 8 | Results for case 1. (A) Frequency. (B) Active power. (C) Pitch angle. 

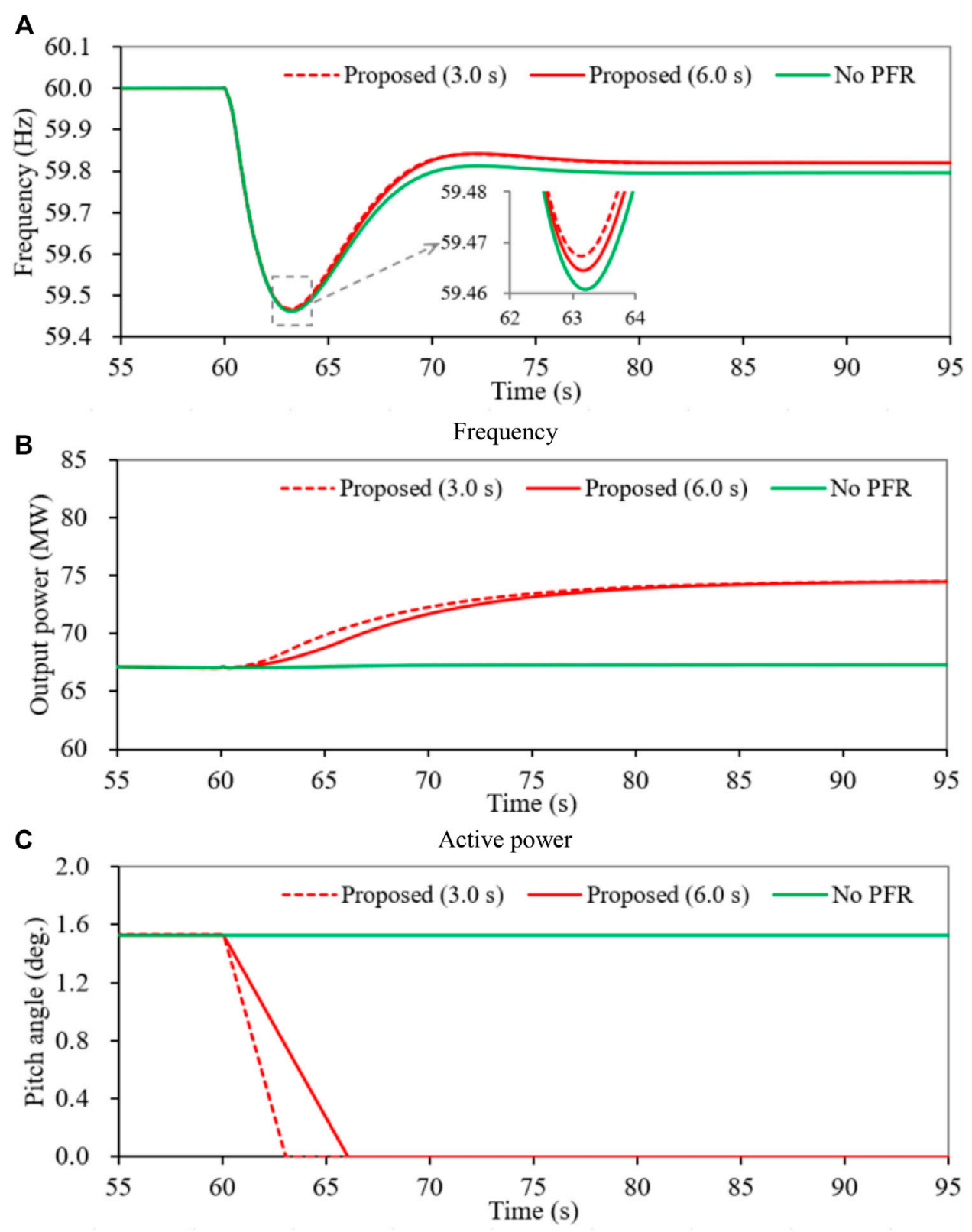

Pitch angle

FIGURE 9 | Results for case 2. (A) Frequency. (B) Active power. (C) Pitch angle.

conditions and wind power penetration levels are carried out. Wind power penetration levels are respectively $15 \%$ for Case 1 and Case 2, and 30\% for Case 3.

\section{Case 1: Wind Speed of $8.0 \mathrm{~m} / \mathrm{s}$ With $10 \%$ De-Loaded Operation, Wind Power Penetration Level of $15 \%$}

Figure 8 illustrates the simulation results for Case 1. To achieve spinning reserve power of $10 \%$, the pitch angle control increases the pitch angle to $1.54^{\circ}$. When $\mathrm{CSG}_{4}$ generates $65 \mathrm{MW}$ is tripped out from the electric power gird, the maximum frequency deviation for the DFIG without PFR is $0.539 \mathrm{~Hz}$; in this case, there is no change on the pitch angle and the output of the DFIG. When the DFIG implements the proposed PFR strategies with a small $\Delta t$ and with a large $\Delta t$, the maximum frequency deviations are $0.537 \mathrm{~Hz}$ and $0.538 \mathrm{~Hz}$, respectively, as shown in Figure 8A. The improvements of the maximum frequency nadir for the proposed enhanced PFR strategies with different $\Delta t$ are higher by 0.002 and $0.001 \mathrm{~Hz}$ in comparison with no PFR strategy, respectively, since the output power of the DFIG gradually increases and the rate of output power of the DFIG for the 

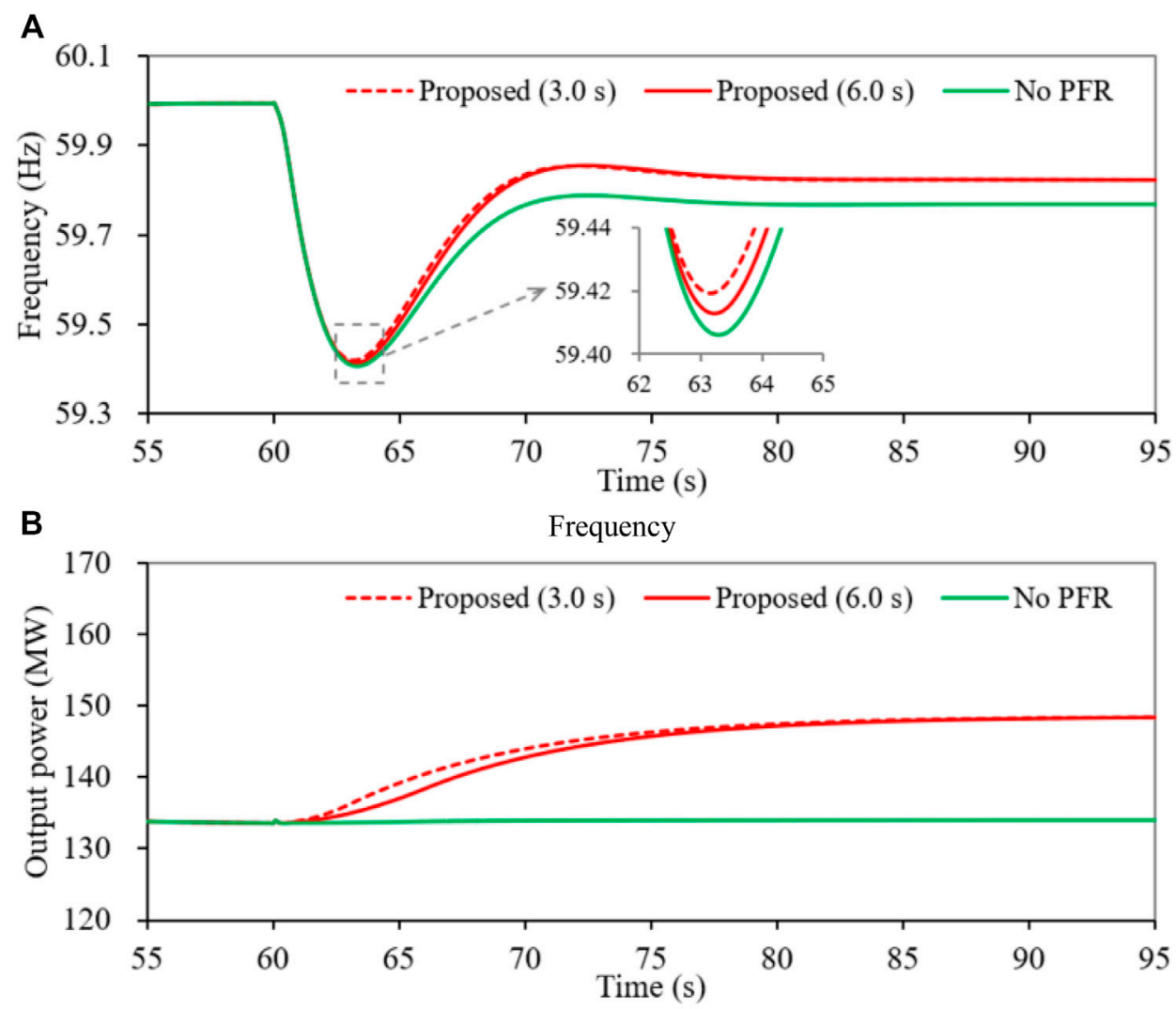

C

Active power

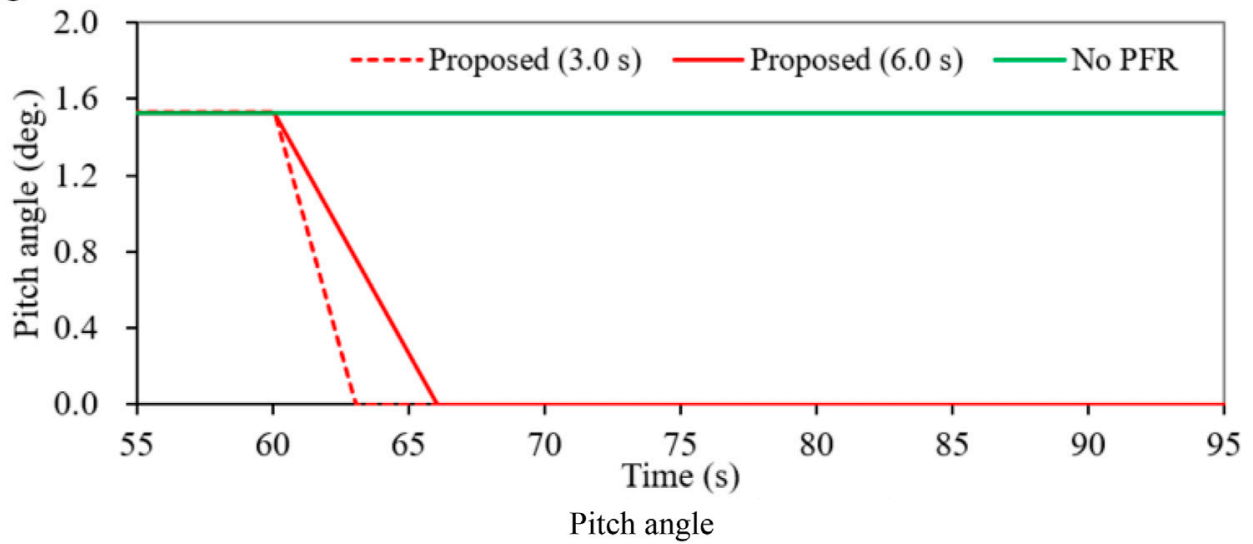

FIGURE $\mathbf{1 0}$ | Results for case 3. (A) Frequency. (B) Active power. (C) Pitch angle.

proposed PFR strategy with a small $\Delta t$ is more than in the proposed PFR strategy with a large $\Delta t$ (Figure $8 \mathrm{C}$ ). The settling frequency for the proposed PFR strategy is $59.808 \mathrm{~Hz}$; this is more than that of no PFR strategy by $0.013 \mathrm{~Hz}$ due to the more power generation of 3.7 MW.

As shown in Figure 8B, the DFIG decreases the pitch angle from 1.53 to $0^{\circ}$ during 3.0 and $6.0 \mathrm{~s}$ for the proposed enhanced PFR strategy, respectively. Thus, the DFIG increases it output power gradually from 34.7 to $38.4 \mathrm{MW}$ for compensating the power deficit. On the other hand, there is no change for the pitch angle and output power of the DFIG based wind farm in no PFR.

\section{Case 2: Wind Speed of $10.0 \mathrm{~m} / \mathrm{s}$ With $10 \%$ De-Loaded Operation, Wind Power Penetration Level of $15 \%$}

Figure 9 illustrates the simulation results for Case 2. Similar to previous case, to achieve $10 \%$ spinning reserve power, the pitch 
angle control almost increases the pitch angle to $1.53^{\circ}$. The maximum frequency deviation for the DFIG without PFR is $0.539 \mathrm{~Hz}$, which is almost the same as in Case 1 due to the same size of disturbance and no response from the DFIG.

The maximum frequency deviation of the proposed PFR strategy with a small $\Delta t$ and with a large $\Delta t$, the maximum frequency deviations are 0.533 and $0.536 \mathrm{~Hz}$, respectively, as shown in Figure 8A. The improvements of the maximum frequency nadir for the proposed enhanced PFR strategies with different $\Delta t$ are higher by 0.006 and $0.003 \mathrm{~Hz}$ in comparison with no PFR strategy, respectively, since the rate of output power of the DFIG for the proposed PFR strategy with a small $\Delta t$ is more than in the proposed PFR strategy with a large $\Delta t$ (Figure 8C). The settling frequency for the proposed PFR strategy is $59.820 \mathrm{~Hz}$; this is more than that of no frequency regulation strategy by $0.025 \mathrm{~Hz}$ due to the more power generation of 7.5 MW.

Compared with Case 1, as in Case 1, the DFIG decreases the pitch angle from $1.53^{\circ}$ to $0^{\circ}$ during 3.0 and $6.0 \mathrm{~s}$ for the proposed enhanced PFR strategy, respectively. However, the amount of increase power of the DFIG is $7.5 \mathrm{MW}$, which is more than that of Case 1 so that the settling frequency is $0.012 \mathrm{~Hz}$ higher and the maximum frequency deviations are less. Thus, as the wind speed increases, the proposed enhanced PFR strategy can improve the performance in terms of reducing the maximum frequency deviation and increasing the settling frequency.

\section{Case 3: Wind Speed of $10.0 \mathrm{~m} / \mathrm{s}$ With $10 \%$ De-Loaded Operation, Wind Power Penetration Level of $\mathbf{3 0} \%$}

Figure 10 illustrates the simulation results for Case 3 with a high wind power penetration compared to Case 2. The maximum frequency deviation for the DFIG without PFR is $0.594 \mathrm{~Hz}$ and is less than Case 1 and Case 2 due to the reduced frequency support capability. The DFIG with the proposed enhanced PFR strategy increases it output power from 133.6 to $148.4 \mathrm{MW}$ with various rates by decreasing the pitch angle from $1.53^{\circ}$ to $0^{\circ}$ during 3.0 and $6.0 \mathrm{~s}$, respectively. As a result, the maximum frequency deviation of the proposed PFR strategy with a small $\Delta t$ is $0.581 \mathrm{~Hz}$, which is $0.006 \mathrm{~Hz}$ more than that of the proposed PFR strategy with a large $\Delta t$. Furthermore, the improvement of the maximum frequency deviation is more than that of Case 2 because of the higher wind power penetration level. In addition, the settling frequencies for the proposed PFR strategy are the same due to the same amount of increase output power of the DFIG; moreover, it is $0.054 \mathrm{~Hz}$ more than in no frequency regulation strategy and $0.003 \mathrm{~Hz}$ more than that of Case 2, even though the PFR of the CSGs becomes worse.

As the growing wind power penetration levels, the proposed PFR strategy can improve the frequency maximum frequency deviation and settling frequency in comparison with low wind penetration levels.

\section{CONCLUSION}

This paper suggests an improved PFR strategy of the DFIG based on the pitch angle control to reduce the maximum frequency deviation and improve the settling frequency. To address this, a function of the pitch angle is employed that decreases the pitch angle with time to feed the active power to the power gird. The DFIG works in de-loaded operation with a certain reserve power for frequency regulation via pitch angle control prior to disturbances. The contributions of the proposed PFR are as follows:

1) The function of the pitch angle is defined in the time domain so as to regulate the participating time of the PFR.

2) The proposed PFR scheme can smoothly increase the output power to improve the PFR capability.

Simulation results on various wind speed conditions and penetration levels successfully illustrated that the proposed PFR strategy can reduce the maximum frequency deviation and improve the settling frequency. As the increasing wind speed conditions and wind power penetration level, the improvement of the maximum frequency deviation and settling frequency become better.

In future, the authors would focus on designing the optimal primary frequency response of the DFIG with the maximum rotor kinetic energy (Shi et al., 2018).

\section{DATA AVAILABILITY STATEMENT}

The raw data supporting the conclusion of this article will be made available by the authors, without undue reservation.

\section{AUTHOR CONTRIBUTIONS}

$\mathrm{XS}$ and XW conducted the back ground research of the project. FY, HY, and DJ proposed the methodology of the project. XS, $\mathrm{XW}, \mathrm{YX}$, and DJ completed the main theory and simulation content. XS and XW completed the writing of the paper. The work was supported by the fund of XS, FY, and HY.

\section{FUNDING}

This work was supported by the Technology Project of Alpha ESS Co., Ltd. (21ZH479). 


\section{REFERENCES}

Attya, A. B., Dominguez-Garcia, J. L., and Anaya-lara, O. (2018). A Review on Frequency Support Provision by Wind Power Plants: Current and Future Challenges. Renew. Sust. Energ. Rev. 81, 2071-2087. doi:10.1016/j.rser.2017.06.016

Aziz, A., Than Oo, A., and Stojcevski, A. (2018). Frequency Regulation Capabilities in Wind Power Plant. Sustainable Energ. Tech. Assessments 26, 47-76. doi:10.1016/j.seta.2017.10.002

Bevrani, H. (2009). "Real Power Compensation and Frequency Control," in Robust Power System Frequency Control (New York: Springer Science Business Media, LLC), 15-37.

Byerly, R. T., Aanstad, O., Berry, D. H., Dunlop, R. D., Ewart, D. N., Fox, B. M., et al. (1973). Dynamic Models for Steam and Hydro Turbines in Power System Studies. IEEE Trans. Power App. Syst. PAS-92 (6), 1904-1915.

Eto, J. H., Undrill, J., Mackin, P., Daschmans, R., Williams, B., Haney, B., et al. (2010). Use of Frequency Response Metrics to Assess the Planning and Operating Requirements for Reliable Integration of Variable Renewable Generation. Berkeley, CA, USA: Lawrence Berkeley National Laboratory. Tech. Rep. LBNL-4142E.

Fu, Y., Zhang, X., Hei, Y., and Wang, H. (2017). Active Participation of Variable Speed Wind Turbine in Inertial and Primary Frequency Regulations. Electric Power Syst. Res. 147, 174-184. doi:10.1016/j.epsr.2017.03.001

Hansen, A. D., Altin, M., and Iov, F. (2016). Provision of Enhanced Ancillary Services from Wind Power Plants - Examples and Challenges. Renew. Energ. 97, 8-18. doi:10.1016/j.renene.2016.05.063

$\mathrm{Hu}$ J., Shao, C., Wang, W., Xu, G., Dong, C., and Bi, T. (2019). “A Fast Frequency Control Strategy for Deloaded WTG in the 303 Power System with High Penetration of Renewable Energy," in Proceeding of the 2019 IEEE Innovative Smart Grid Technologies - Asia 304 (ISGT Asia), Chengdu, China, May 2019 (IEEE), 4036-4041.

Hydro Québec TransÉnergie (2009). Transmission Provider Technical Requirements for the Connection of Power Plants to the Hydro Québec Transmission System. Québec: Montréal.

Kheshti, M., Ding, L., Nayeripour, M., Wang, X., and Terzijia, V. (2019). Active Power Support of Wind Turbines for Grid Frequency Events Using a Reliable Power Reference Scheme. Renew. Energ. 139, 1421-1454. doi:10.1016/ j.renene.2019.03.016

Kim, J., Muljadi, E., Gevorgian, V., and Hoke, A. F. (2019). Dynamic Capabilities of an Energy Storage-Embedded DFIG System. IEEE Trans. Ind. Applicat. 55 (4), 4124-4134. doi:10.1109/tia.2019.2904932

Kundur, P. (1994). Power System Stability and Control Electric Power Research Institute. New York: McGraw-Hill.

Lee, J., Jang, G., Muljadi, E., Blaabjerg, F., Chen, Z., and Cheol Kang, Y. (2016). Stable Short-Term Frequency Support Using Adaptive Gains for a DFIG-Based Wind Power Plant. IEEE Trans. Energ. Convers. 31 (3), 1068-1079. doi:10.1109/ tec.2016.2532366

Li, W., Du, P., and Lu, N. (2018). Design of a New Primary Frequency Control Market for Hosting Frequency Response reserve Offers from Both Generators and Loads. IEEE Trans. smart grid 9, 4883-4892. in press. doi:10.1109/tsg.2017.2674518

Li, Y., Gao, W., Yan, W., Huang, S., Wang, R., Gevorgian, V., et al. (2021). Datadriven Optimal Control Strategy for Virtual Synchronous Generator via Deep Reinforcement Learning Approach. J. Mod. Power Syst. 9 (4), 919-929. doi: $10.35833 /$ mpce. 2020.000267

Muljadi, E., and Butterfield, C. P. (2001). Pitch-controlled Variable-Speed Wind Turbine Generation. IEEE Trans. Ind. Applicat. 37 (1), 240-246. doi:10.1109/ 28.903156

Nasirpour, N., Madani, S. M., Niroomand, M., and Muljadi, E. (2021). Closed-loop Fast Primary Frequency-Response of Type-3 Wind Power Plants in Low Inertia Grids. IET Renew. Power Gener. 15, 2931-2943. doi:10.1049/rpg2.12226

North American Electric Reliability Corporation (2015). Reliability Guideline: Primary Frequency Control.

Sarasúa, J. I., Pérez-Díaz, J. I., Martínez-Lucas, G., and Fernández-Muñoz, D. (2021). Simplified Event-Based Load Shedding Scheme for Frequency Stability in an Isolated Power System with High Renewable Penetration.
El Hierro: A Case Study. Front. Energ. Res. 9, 698081. doi:10.3389/ fenrg.2021.698081

Shi, Q., Li, F., and Cui, H. (2018). Analytical Method to Aggregate MultiMachine SFR Model with Applications in Power System Dynamic Studies. IEEE Trans. Power Syst. 33 (6), 6355-6367. doi:10.1109/ tpwrs.2018.2824823

Shi, Q., Liu, L., Wang, Y., Lu, Y., Zou, Q., Zhang, Q., et al. (2021). Cooperative Synthetic Inertia Control for Wind Farms Considering Frequency Regulation Capability. Front. Energ. Res. 9, 738857. doi:10.3389/ fenrg.2021.738857

Vidyanandan, K. V., and Senroy, N. (2014). Closure to Discussion on "Primary Frequency Regulation by Deloaded Wind Turbines Using Variable Droop". IEEE Trans. Power Syst. 29 (1), 414-415. doi:10.1109/tpwrs.2013.2290822

Vidyanandan, K. V., and Senroy, N. (2013). Primary Frequency Regulation by Deloaded Wind Turbines Using Variable Droop. IEEE Trans. Power Syst. 28 (2), 837-846.

Wang, R., Sun, Q., Tu, P., Xiao, J., Gui, Y., and Wang, P. (2021). Reduced-Order Aggregate Model for Large-Scale Converters with Inhomogeneous Initial Conditions in DC Microgrids. IEEE Trans. Energ. Convers. 36 (3), 2473-2484. doi:10.1109/tec.2021.3050434

Yang, D., Jin, Z., Zheng, T., and Jin, E. (2022). An Adaptive Droop Control Strategy with Smooth Rotor Speed Recovery Capability for Type III Wind Turbine Generators. Int. J. Electr. Power Energ. Syst. 135, 107532. doi:10.1016/ j.ijepes.2021.107532

Yang, D., Kim, J., Kang, Y. C., Muljadi, E., Zhang, N., Hong, J., et al. (2018). Temporary Frequency Support of a DFIG for High Wind Power Penetration. IEEE Trans. Power Syst. 33 (3), 3428-3437. doi:10.1109/ tpwrs.2018.2810841

Ye, Y., Qiao, Y., and Lu, Z. (2019). Revolution of Frequency Regulation in the Converter-Dominated Power System. Renew. Sust. Energ. Rev. 111, 145-156. doi:10.1016/j.rser.2019.04.066

Zhang, N., Sun, Q., Wang, J., and Yang, L. (2021). Distributed Adaptive Dual Control via Consensus Algorithm in the Energy Internet. IEEE Trans. Ind. Inform. 17, 4848-4860. in press. doi:10.1109/tii.2020.3031437

Zhong, C., Lv, Y., Zhou, Y., and Li, H. (2021). An Equivalent Rotor Speed Compensation Control of PMSG-Based Wind Turbines for Frequency Support in Islanded Microgrids. Front. Energ. Res. 9, 717327. doi:10.3389/ fenrg.2021.717327

Zhu, Q., Wang, Y., Song, J., Jiang, L., and Li, Y. (2021). Coordinated Frequency Regulation of Smart Grid by Demand Side Response and Variable Speed Wind Turbines. Front. Energ. Res. 9, 754057. doi:10.3389/fenrg.2021.754057

Conflict of Interest: XS, FY, and HY were employed by the company Alpha ESS Co., Ltd. The authors declare that this study received funding from Alpha ESS Co., Ltd. (21ZH479). The company had the following involvement in the study: back ground research, methodology and writing-original draft preparation.

The remaining authors declare that the research was conducted in the absence of any commercial or financial relationships that could be construed as a potential conflict of interest.

Publisher's Note: All claims expressed in this article are solely those of the authors and do not necessarily represent those of their affiliated organizations, or those of the publisher, the editors and the reviewers. Any product that may be evaluated in this article, or claim that may be made by its manufacturer, is not guaranteed or endorsed by the publisher.

Copyright (c) 2022 Si, Wu, You, Yuan, Xu and Yang. This is an open-access article distributed under the terms of the Creative Commons Attribution License (CC BY). The use, distribution or reproduction in other forums is permitted, provided the original author(s) and the copyright owner(s) are credited and that the original publication in this journal is cited, in accordance with accepted academic practice. No use, distribution or reproduction is permitted which does not comply with these terms. 